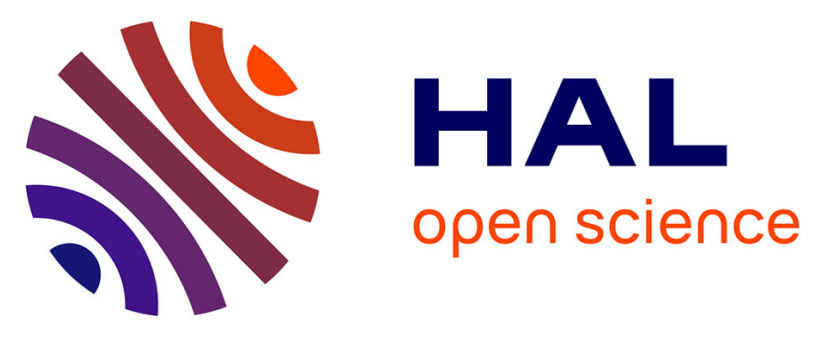

\title{
Modulation of in vitro antimalarial responses by polymorphisms in Plasmodium falciparum ABC transporters (pfmdr1 and pfmdr5)
}

Mathieu Gendrot, Mamadou Wague Gueye, Francis Tsombeng Foguim, Marylin Madamet, Khalifa Ababacar Wade, Mame Bou Kounta, Mansour Fall, Silman Diawara, Nicolas Benoit, Gora Lo, et al.

\section{To cite this version:}

Mathieu Gendrot, Mamadou Wague Gueye, Francis Tsombeng Foguim, Marylin Madamet, Khalifa Ababacar Wade, et al.. Modulation of in vitro antimalarial responses by polymorphisms in Plasmodium falciparum ABC transporters (pfmdr1 and pfmdr5). Acta Tropica, 2019, 196, pp.126-134. 10.1016/j.actatropica.2019.05.020 . hal-02140933

\section{HAL Id: hal-02140933 \\ https://hal.science/hal-02140933}

Submitted on 25 Oct 2021

HAL is a multi-disciplinary open access archive for the deposit and dissemination of scientific research documents, whether they are published or not. The documents may come from teaching and research institutions in France or abroad, or from public or private research centers.
L'archive ouverte pluridisciplinaire HAL, est destinée au dépôt et à la diffusion de documents scientifiques de niveau recherche, publiés ou non, émanant des établissements d'enseignement et de recherche français ou étrangers, des laboratoires publics ou privés.

\section{(ㄷ)(1) $\$$}

Distributed under a Creative Commons Attribution - NonCommerciall 4.0 International 
1 Modulation of in vitro antimalarial responses by polymorphisms in Plasmodium

2 falciparum $\mathrm{ABC}$ transporters (pfmdr1 and pfmdr5)

3

4 Mathieu Gendrot ${ }^{\mathrm{a}, \mathrm{b}, \mathrm{c}}$, Mamadou Wague Gueye ${ }^{\mathrm{d}}$, Francis Tsombeng Foguim, ${ }^{\mathrm{a}, \mathrm{b}, \mathrm{c}}$, Marylin

5 Madamet $^{\mathrm{a}, \mathrm{b}, \mathrm{c}, \mathrm{e}}$, Khalifa Ababacar Wade ${ }^{\mathrm{f}}$, Mame Bou Kounta ${ }^{\mathrm{f}}$, Mansour Fall ${ }^{\mathrm{g}}$, Silman

6 Diawara $^{\mathrm{d}}$, Nicolas Benoit ${ }^{\mathrm{a}, \mathrm{b}, \mathrm{c}, \mathrm{e}}$, Gora Lo $^{\mathrm{h}, \mathrm{i}}$, Raymond Bercion ${ }^{\mathrm{j}}$, Rémy Amalvict ${ }^{\mathrm{a}, \mathrm{b}, \mathrm{c}, \mathrm{e}}$, Joel

7 Mosnier ${ }^{\mathrm{a}, \mathrm{b}, \mathrm{c}, \mathrm{e}}$, Bécaye Fall ${ }^{\mathrm{d}}$, Sébastien Briolant ${ }^{\mathrm{a}, \mathrm{b}, \mathrm{c}}$, Bakary Diatta $^{\mathrm{k}}$, Bruno Pradines $^{\mathrm{a}, \mathrm{b}, \mathrm{c}, \mathrm{d}, \mathrm{e} \mathrm{e}^{*}}$

${ }^{a}$ Unité Parasitologie et entomologie, Département Microbiologie et maladies infectieuses,

Institut de recherche biomédicale des armées, Marseille, France

${ }^{b}$ Aix Marseille Univ, IRD, AP-HM, SSA, VITROME, Marseille, France

${ }^{c} I H U$ Méditerranée Infection, Marseille, France

${ }^{d}$ Laboratoire d'étude de la chimiosensibilité du paludisme, Fédération des laboratoires,

Hôpital Principal de Dakar, Dakar, Sénégal

${ }^{e}$ Centre national de référence du Paludisme, Institut hospitalo-universitaire (IHU)

Méditerranée Infection, Marseille, France

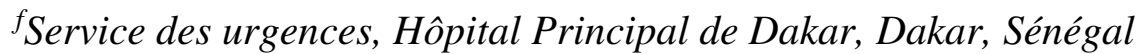

${ }^{g}$ Service de réanimation médicale, Hôpital Principal de Dakar, Dakar, Sénégal

${ }^{h}$ Centre médical interarmées, Dakar, Sénégal

${ }^{i}$ Laboratoire de bactériologie virologie, Université Cheikh Anta Diop, CHU Le Dantec,

Dakar, Sénégal

jLaboratoire d'analyses médicales, Institut Pasteur, Dakar, Sénégal

${ }^{k}$ Chefferie, Hôpital Principal de Dakar, Dakar, Sénégal 
$25 *$ Corresponding author at: Unité Parasitologie et entomologie, Institut de recherche

26 biomédicale des armées, IHU Méditerranée Infection, 19-21 Boulevard Jean Moulin, 13005

27 Marseille, France.

28 E-mail address: bruno.pradines@gmail.com (B. Pradines) 


\section{Abstract}

The emergence of resistance to artemisinin-based combination therapies (ACT) was described in Southeast Asia. In this context, the identification of molecular markers of ACT resistance partner drugs is urgently needed for monitoring the emergence and spread of resistance. Polymorphisms in transporter genes, especially of the ATP-binding cassette (ABC) superfamily, have been involved in anti-malarial drug resistance. In this study, the association between the mutations in the $P$. falciparum multidrug resistance 1 gene ( $p f m d r l, \mathrm{~N} 86 \mathrm{Y}$, Y184F, S1034C, N1042D and D1246Y) or repetitive amino acid motifs in pfmdr5 and the ex vivo susceptibility to anti-malarial drugs was evaluated. Susceptibility to chloroquine, quinine, monodesethylamodiaquine, lumefantrine, piperaquine, pyronaridine, mefloquine and dihydroartemisinin was assessed in 67 Senegalese isolates. The shorter DNNN motif ranged from to 2 to 11 copy repeats, and the longer DHHNDHNNDNNN motif ranged from 0 to 2 in pfmdr5. The present study showed the association between repetitive amino acid motifs (DNNN-DHHNDDHNNDNNN) in pfmdr5 and in vitro susceptibility to 4-aminoquinolinebased antimalarial drugs. The parasites with 8 and more copy repeats of DNNN in $p f m d r 5$ were significantly more susceptible to piperaquine. There was a significant association between parasites whose DHHNDHNNDNNN motif was absent and replaced by DHHNDNNN, DHHNDHNNDHNNDNNN or DHHNDHNNDHNNDHNNDNNN and increased susceptibility to chloroquine, monodesethylamodiaquine and pyronaridine. A significant association between both the wild-type allele N86 in pfmdrl and the N86-184F haplotype and reduced susceptibility to lumefantrine was confirmed. Further studies with a large number of samples are required to validate the association between these $p f m d r 5$ alleles and the modulation of 4-aminoquinoline-based antimalarial drug susceptibility.

Keywords Malaria, Plasmodium falciparum, Antimalarial drug, in vitro, Resistance, Molecular marker, ABC transporter, pfmdr5, pfmdrl 


\section{Introduction}

The spread of antimalarial drug resistance from Southeast Asia to Africa has previously occurred with chloroquine and sulfadoxine-pyrimethamine (Wootton et al., 2002; Mita et al., 2011). The emergence of resistance to artemisinins, as manifested by delayed parasite clearance after artemisinin-based combination therapies (ACT), was described in Southeast Asia (Dondorp et al., 2009; Asley et al., 2014; Ménard et al., 2016). Drug resistance is currently emerging also to dihydroartemisinin-piperaquine, the most recently commercialized ACT, in Cambodia (Leang et al., 2015; Spring et al., 2015; Amaratunga et al., 2016) and in Vietnam (Phuc et al., 2017; Thanh et al., 2017). In areas where artemisinin resistance is emerging, combination efficacy is based now on partner drugs. In this context, it is essential to find novel markers of resistance to monitor the emergence and spread of resistance to these partner drugs.

Gene polymorphisms in the transporter ATP-binding cassette (ABC) superfamily are known to be involved in antimalarial drug resistance (Pradines et al., 2009). Studies of the $P$. falciparum multidrug resistance 1 gene ( $p f m d r l)$ have identified two single-nucleotide polymorphisms (SNPs) which are more prevalent in African and Asian parasites (N86Y and Y184F) and three SNPs which are more common in South American isolates (S1034C, N1042D and D1246Y). The N86Y mutation is involved in parasite susceptibility to most of the partner drugs of ACT, including artemisinin, lumefantrine, amodiaquine, mefloquine and piperaquine (Wurtz et al., 2014; Veiga et al., 2016). The role of these mutations was proved by transfection studies that demonstrated the susceptibility modulation of $P$. falciparum parasites to anti-malarial drugs (Sidhu et al., 2005; Veiga et al., 2016). Additionally, clinical assays in East Africa have shown the selection of the N86 allele in recurrent infections after treatment with artemether plus lumefantrine (Sisowath et al., 2005; Dokomajilar et al., 2006) 
or artesunate plus mefloquine (Price et al., 2004). In Uganda, the use of dihydroartemisininpiperaquine selected for the 86Y mutation (Nankabirwa et al., 2016).

However, SNPs and overexpression of $p f m d r 1$ do not entirely explain responses observed in resistant $P$. falciparum parasites, suggesting that other polymorphisms may be involved in antimalarial drug susceptibility. The $P$. falciparum genome is rich in sequences encoding lowcomplexity regions which comprise repetitions of short motifs. Existence of these repeat polymorphisms has been identified in ABC transporters (Okombo et al., 2013; Veiga et al., 2014). But very few studies explored association between these repeat polymorphisms and parasite susceptibility to anti-malarial drugs. Interestingly, the presence of 7 and 9 Asn repeats in pfmdr6 (PF3D7_1352100) were associated with modulation of in vitro lumefantrine and dihydroartemisinin drug responses in parasites from the China-Myanmar border area (Wang et al., 2012). Parasites with 6 Asn repeats were significantly less susceptible to lumefantrine, whereas those with 8 Asn repeats were less susceptible to piperaquine in parasites collected in Kenya (Okombo et al., 2013). The presence of 7 or 9 Asn repeats was also associated with reduced in vitro susceptibility to quinine in 77 Senegalese $P$. falciparum isolates (Gendrot et al., 2017).

Repetitive amino acid motifs in pfmdr5 (PF3D7_1339900), which codes a protein localized at the plasma membrane of the parasite (Kavishe et al., 2009), were associated with reduced in vitro susceptibility to lumefantrine (Okombo et al., 2013). Additionally, deletion of pfmdr5 in P. falciparum parasites resulted in a minor decrease in the inhibiting concentration $50 \%$ $\left(\mathrm{IC}_{50}\right)$ of artemisinin (van der Velden et al., 2015).

The objectives of this study were to explore the existence of repeat polymorphisms in $p f m d r 5$ in Senegalese isolates and to evaluate the influence of these repetitive amino acid motifs on the ex vivo susceptibilities to ACT partners, including monodesethylamodiaquine (DQ), mefloquine (MQ), lumefantrine (LMF), piperaquine (PPQ), pyronaridine (PND) and 
dihydroartemisinin (DHA), and standard antimalarial drugs, such as chloroquine (CQ) and quinine (QN). The re-affirmation of the established relationships between in vitro properties and $p f m d r l$ will allow to valid the relationships obtained between phenotypes and $p f m d r 5$.

\section{Materials and methods}

\subsection{Patients and sample collection}

Sixty-seven $P$. falciparum isolates from patients with uncomplicated or severe falciparum malaria, who were recruited at the Hôpital Principal de Dakar after the rainy seasons from 2013 to 2015, were successfully evaluated (13 from 2013, 22 from 2014 and 32 from 2015). Among the studied patients, $55(82 \%)$ were recruited from the emergency department and 6 patients $(9 \%)$ had travelled within Senegal in the previous month. Antimalarial treatment prior to admission was not recorded. The patients were treated with quinine until 2014 and then with artesunate, artemether-lumefantrine or artesunate-amodiaquine.

Peripheral venous blood samples were collected in Vacutainer ${ }^{\circledR}$ ACD tubes (Becton Dickinson, Rutherford, NJ) prior to patient treatment. The parasitemia, ranged from 0.006 to $14.1 \%$, was estimated on thin blood smears that were stained using a RAL ${ }^{\circledR}$ kit (Réactifs RAL, Paris, France).

\subsection{Drugs}

CQ, QN and DHA were obtained from Sigma (Saint Louis, MO, USA), DQ from the World Health Organization (Geneva, Switzerland), MQ from Roche (Paris, France), LMF from Novartis Pharma (Basel, Switzerland), and PPQ and PND from Shin Poong Pharm Co (Seoul, Korea). QN, DQ, MQ, DHA and PPQ were first dissolved in absolute methanol and then diluted in water to final concentrations that ranged from 6 to 3,149 nM for QN (stock solution $31,490 \mathrm{nM}$ ), 1.9 to $1,988 \mathrm{nM}$ for DQ (stock solution $19,880 \mathrm{nM}$ ), 1.5 to $392 \mathrm{nM}$ for MQ 
(stock solution 40,000 nM), 0.1 to $107 \mathrm{nM}$ for DHA (stock solution 26,750 nM) and 1.9 to $998 \mathrm{nM}$ for PPQ (stock solution 10,000 nM). CQ and PND were resuspended and diluted in water to final concentrations ranging from 6 to $3,231 \mathrm{nM}$ and 0.4 to $199 \mathrm{nM}$, respectively.

LMF was resuspended and diluted in absolute ethanol to obtain final concentrations ranging from 0.6 to $310 \mathrm{nM}$ (stock solution 3,000 nM).

Each batch of plates were validated on the CQ-resistant W2 strain (isolated in Indochina; ref MRA-157 obtained from MR4, VA) in four independent experiments using the same conditions described below. The mean $\mathrm{IC}_{50}$ values for the chloroquine-resistant $\mathrm{W} 2$ strain for the different batches used during the three years were $292 \mathrm{nM}$ for CQ, $275 \mathrm{nM}$ for QN, $72 \mathrm{nM}$ for DQ, 13.7 nM for LMF, 15.4 nM for MQ, $32.5 \mathrm{nM}$ for PPQ, 26.4 nM for PND and 1.27 $\mathrm{nM}$ for DHA. A comparison of W2 susceptibility data for the nine anti-malarial drugs indicated that there was no significant difference in the responses to antimalarial drugs over the three years $(0.39<\mathrm{p}<0.95)$.

The polymorphic genetic markers $m s p 1$ and $m s p 2$ and microsatellite markers specific to $P$. falciparum were genotyped at least once a month to verify W2 clonality (Bogreau et al., 2006; Henry et al., 2006).

\subsection{Ex vivo assay}

The susceptibility of the 67 isolates to the eight antimalarial drugs was once assessed by ELISA sandwich based assay targeting the P. falciparum histidin-rich protein 2 antigen without culture adaptation as previously described (Fall et al., 2015; Gendrot et al., 2016). For the ex vivo assay, $100 \mu \mathrm{l}$ of parasitized red blood cells (final parasitaemia, $0.5 \%$; final haematocrit, $1.5 \%$ ) was aliquoted into the 96-well plates pre-dosed with antimalarial drugs. The cut-off values for the reduced in vitro susceptibility or resistance were as follows: $77 \mathrm{nM}$ 
(CQ), $611 \mathrm{nM}(\mathrm{QN}), 61 \mathrm{nM}(\mathrm{DQ}), 30 \mathrm{nM}$ (MQ), $115 \mathrm{nM}$ (LMF), $135 \mathrm{nM}$ (PPQ), $60 \mathrm{nM}$ (PND) and 12 nM (DHA) (Fall et al., 2011; Pascual et al., 2015).

\subsection{Nucleic acid extraction}

The total genomic DNA of each isolate was isolated using the QIAamp DNA Blood minikit according to the manufacturer's recommendations (Qiagen, Hilden, Germany).

\subsection{Gene sequence polymorphism analysis}

Two genes, pfmdr5 (PF3D7_1339900), and pfmdrl (PF3D7_0523000) were amplified by polymerase chain reaction using the oligonucleotide primer pairs described in Table 1 . The primers used amplified a region of $p f m d r 5$ gene of about $900 \mathrm{bp}$. Two primer pairs were used to amplify the $p f m d r l$ fragments carrying the five mutations in two regions of $610 \mathrm{pb}$ and 890 pb. The reaction mixture consisted of $200 \mathrm{ng}$ of genomic DNA, $0.32 \mu \mathrm{M}$ of each primer, $1 \mathrm{X}$ final of reaction buffer $\left(750 \mathrm{mM}\right.$ Tris- $\mathrm{HCl}, 200 \mathrm{mM}\left(\mathrm{NH}_{4}\right)_{2} \mathrm{SO}_{4}, 0.1 \%(\mathrm{v} / \mathrm{v})$ Tween 20 and stabilizer, $\mathrm{pH} 8.8$ ), $200 \mu \mathrm{M}$ of deoxynucleoside triphosphate mixture (dGTP, dATP, dTTP and dCTP) (Euromedex, Souffelweyersheim, France), variable concentrations of $\mathrm{MgCl}_{2}$ (Table 1) and 0.2 U of Red Diamond Taq ${ }^{\circledR}$ polymerase (Eurogentec, Liège, Belgium) in a final volume of $25 \mu \mathrm{L}$. The thermal cycler (T3 Biometra, Biometra Gmbh, Göttingen, Germany) was programmed as follows: $94^{\circ} \mathrm{C}$ for $10 \mathrm{~min}$, then 40 cycles alternating among $94^{\circ} \mathrm{C}$ for $30 \mathrm{sec}$, hybridization temperature (Table 1) for $45 \mathrm{sec}$, and $72^{\circ} \mathrm{C}$ for extension at $1 \mathrm{~min}$ per $1,000 \mathrm{bp}$, followed by a 10 -min final extension step at $72^{\circ} \mathrm{C}$. The amplified products were sequenced using the PCR primers on an ABI Prism 3100 analyzer (Applied Biosystems) according to the manufacturer's instructions. The Vector NTI advance (TM) software (version 11, Invitrogen, Cergy Pontoise, France) was used to perform data analysis. 
The whole amplicons obtained were analyzed to identify any other possible single nucleotide polymorphism (SNP).

Poor-quality sequences were either resequenced or discarded and repeat polymorphisms were retained for analysis if clean individual peaks were observed in the electropherogram. Mixed genotypes were excluded from further analysis.

\subsection{Statistical analysis}

In this study, the association between the mutations in pfmdrl (N86Y, Y184F, S1034C, N1042D and D1246Y) or repetitive amino acid motifs in $p f m d r 5$ and the ex vivo susceptibility to antimalarial drugs was evaluated. The data were analyzed using the $\mathrm{R}$ software (version 3.0.2). Differences in the $\mathrm{IC}_{50} \mathrm{~s}$ of the isolates and the $p f m d r 5$ and $p f m d r l$ polymorphisms were compared using the Kruskal-Wallis test and the Welch two-sample $t$ test. The differences between susceptible and resistant $P$. falciparum parasites and polymorphisms were analyzed by logistic regression. The significance level was calculated using the correction of Bonferroni. The significance threshold retained for $p f m d r 5$ analysis was 0.007 .

\section{Results}

The distribution and the average parameters of the $\mathrm{IC}_{50}$ values for the eight antimalarial drugs are presented in Table 2 and Fig. 1.

\subsection{Pfmdr5}

Fourteen different allelic groups were identified in the 67 isolates that were genotyped at pfmdr5 (Table 3). The shorter DNNN motif ranged from to 2 to 11. 
The longer DHHNDHNNDNNN motif exited in single- or double-copy repeat. This motif was not found in 5 isolates (7.5\%) and was replaced by DHHNDNNN (4.5\%),

DHHNDHNNDHNNDNNN (1.5\%) and DHHNDHNNDHNNDHNNDNNN (1.5\%) motifs.

No new SNP was identified the Senegalese $P$. falciparum parasites.

The proportion of isolates with the dominant allele was $25.5 \%$ (allele $5-1$ ), $23.9 \%$ (allele 61), $19.4 \%$ (allele 7-1), $9.0 \%$ (allele $8-1$ ) and $4.5 \%$ (allele 3-0).

The 8 DNNN -1 DHHNDHNNDNNN (8-1) allele showed a significant association with increased susceptibility to PPQ (30.6 versus $54.3 \mathrm{nM}$; $\mathrm{p}=0.042$; Welch two-sample $t$ test) (Fig. 2A). There was a significant association between parasites with 8 and more than 8 DNNN motifs and increased susceptibility to PPQ (14.0 versus $40.6 \mathrm{nM} ; \mathrm{p}=0.003$ ) or PND (2.7 versus $10.5 \mathrm{nM} ; \mathrm{p}=0.04$ ) (Fig. 2B). After Bonferroni correction, only parasites with 8 and more than 8 motif repeats were significantly more susceptible to PPQ. There was a significant association between the allele 3-0 and increased susceptibility to CQ (30.8 versus $117.0 \mathrm{nM}$; $\mathrm{p}<0.001)$, DQ (10.7 versus $39.3 \mathrm{nM} ; \mathrm{p}<0.001)$, PND (5.1 versus $15.2 \mathrm{nM}$; $\mathrm{p}<0.001)$ and MQ (18.5 versus $37.0 \mathrm{nM} ; \mathrm{p}=0.021$ ). After Bonferroni correction, allele 3-0 was associated only with increased susceptibility to CQ, DQ and PND. This study also showed a significant association between the alleles n-0 (alleles $3-0+7-0+8-0$ ) and increased susceptibility to CQ (28.2 versus $120.0 \mathrm{nM} ; \mathrm{p}<0.001)$, DQ (8.3 versus $40.4 \mathrm{nM} ; \mathrm{p}<0.001)$, PND (6.0 versus 15.5 $\mathrm{nM} ; \mathrm{p}<0.001)$ and LMF (2.4 versus $7.7 \mathrm{nM} ; \mathrm{p}=0.037)$. After Bonferroni correction, significant association was retained only for CQ, DQ and PND.

\subsection{Pfmdr1}

The 1034C, 1042D and 1246Y pfmdrl mutations were not found. No new SNP was identified the Senegalese $P$. falciparum parasites. The $86 \mathrm{Y}$ mutation in $p f m d r l$, identified in $5.5 \%$ of the samples, was significantly associated with increased susceptibility to LMF (2.1 versus 9.9 
nM; $\mathrm{p}=0.002$; Welch two-sample $t$ test) (Table 4) (Fig. 3). However, this result should be taken with caution due to the low frequency of the 86Y SNP. There was no significant difference in $\mathrm{IC}_{50}$ between the isolates with Y184-184F haplotype ( $\mathrm{p}$ values from 0.062 to 0.956; Welsh two-sample $t$ test). Nevertheless, there was a significant association between the N86-184F haplotype, identified in 53\% of the samples, and decreased susceptibility to LMF (12.3 versus $6.3 \mathrm{nM} ; \mathrm{p}=0.049)$ (Fig. 4).

\subsection{Pfmdr5/pfmdr1}

There was no significant association between the alleles n-0 (alleles 3-0 + 7-0 + 8-0), 8-1 or $\geq 8$-x and the N86Y-Y184F haplotypes in pfmdrl ( $\mathrm{p}=0.982$; Pearson's Chi-squared test).

\section{Discussion}

The emergence of resistance to ACT in Southeast Asia (Dondorp et al., 2009; Asley et al., 2014; Ménard et al., 2016), even to the most recently commercialized DHA-PPQ in Southeast Asia (Amaratunga et al., 2016; Phuc at al., 2017), needs the identification of molecular markers of resistance to ACT partner drugs for monitoring emergence and spread of resistance (Parobek et al., 2017).

$\mathrm{ABC}$ transporters have been involved in antimalarial drug resistance. PfMDR5 is a transporter that belongs to the ABC B family, like PfMDR1, PfMDR2 or PfMDR6. However, PfMDR5 is a half transporter and contains only one membrane domain (MD) with 6 putative $\alpha$-helical transmembrane segments (TMS) and only one nucleotide-binding domain (NBD) containing the "Walker A" and the "Walker B" motifs and a short but highly conserve sequence which is typical for the members of the ABC family (Kavishe et al., 2009; Pradines et al., 2005; Pradines et al., 2009). The repetitive amino acid motifs analyzed in this study, DNNN and DHHNDDHNNDNNN, which occurred within a 180 bp region of the open 
reading frame of $p f m d r 5$, are located in the NBD (repeat position above 520 amino acids).

Polymorphisms on gene region encoding the NBD of ABC B transporters have already been shown to be involved in antimalarial drug resistance. The $1246 \mathrm{Y}$ mutation in pfmdrl gene, which is located in the NBD2 is selected in association with a mutation at codon $86(86 \mathrm{Y})$ and an absence of mutation in codon 184 (Y184) in resistance to dihydroartemisinin-piperaquine treatment (Pillai et al., 2012; Taylor et al., 2016). Polymorphisms in NBD region might be involved in resistance to antimalarial drugs. This study showed that the repetitive amino acid motifs were associated with an increased susceptibility to antimalarial drugs. The shorter DNNN motif ranged from 2 to 11 copy repeats, and the longer DHHNDHNNDNNN motif, commonly present in single- or double-copy repeats, was replaced by other motifs in 5 isolates $(7.5 \%)$. This change in longer motif was not found in isolates that were collected in Kilifi, Kenya (Okombo et al., 2013). Among the 14 different allelic groups identified in this study, 7 alleles have never been identified (alleles 2-2, 3-0, 3-1, 3-2, 7-0, 8-0 and 11-1). Except for allele 3-0 (4.5\%), the alleles which were mostly identified in Senegalese $P$. falciparum isolates, were the same alleles as previously observed in Kenyan parasites: allele 5-1 (25.5\% versus $32.8 \%$ in Kenyan isolates), allele 6-1 (23.9\% versus $10.3 \%)$, allele $7-1$ (19.4\% versus $25.9 \%)$ and allele 8-1 (9.0\% versus 17.2\%) (Okombo et al., 2013). However, the proportions for the most frequent alleles were different between Dakar, Senegal and Kilifi, Kenya. Additionally, the most frequent alleles observed in $P$. falciparum referent strains from Africa, Asia or South America were 5-1, 7-1 or 8-1 (Okombo et al., 2013).More generally, parasites with 8 and more than 8 short motifs were significantly more susceptible to PPQ than isolates with less short motifs. None of the parasites bearing 8 and more than 8 short motifs showed reduced susceptibility to PPQ ( $\left.\mathrm{IC}_{50}>135 \mathrm{nM}\right)$. Okombo and colleagues found that allele 5-1 was significantly associated with an increased LMF $\mathrm{IC}_{50}$ on Kenyan isolates, but without correction of the threshold of significance in multiple comparisons (Okombo et al., 
2013). In our study on Senegalese isolates, no significant associations were found between the allele 5-1 and antimalarial drug susceptibility. Parasites with the DHHNDHNNDNNN motif replaced by DHHNDNNN (3-0 allele), DHHNDHNNDHNNDNNN (8-0 allele) and DHHNDHNNDHNNDHNNDNNN (7-0 allele) were significantly more susceptible to CQ, QN and PND, antimalarial drugs that contain a 4-aminoquinoline based chemical core. However, these results came from a limited number of samples. Further studies with a larger number of samples are required to validate the association between these $p f m d r 5$ alleles and the modulation of antimalarial drug susceptibility. Pfmdr5 seems to be not linked with $p f m d r 1$ SNP. However, biochemical studies will be required to eliminate the hypothesis that $p f m d r 5$ may be linked to another gene which has a genuine effect on anti-malarial responses and may be not involved in resistance.

The pfmdrl N86 was significantly associated with decreased susceptibility to LMF (9.9 versus $2.1 \mathrm{nM}$ ). However, this result should be taken with caution due to the low frequency of the 86Y SNP. But this result is in accordance with previous in vitro studies in Asia (Mungthin et al., 2010), Kenya (Mwai et al., 2009), Benin (Dahlström et al., 2014) and Senegal (Wurtz et al., 2014). The role of N86Y mutation in LMF susceptibility modulation was proved by transfection study (Veiga et al., 2016). Additionally, clinical assays in Africa have shown the selection of the N86 allele in recurrent infections after treatment with artemether-lumefantrine (Baraka et al., 2015; Sondo et al., 2016). The presence of the N86 mutation was a risk factor for recrudescence in patients who were treated with artemether-lumefantrine (Venkatesan et al., 2014).

Furthermore, there was a significant association between the N86-184F haplotype and decreased susceptibility to LMF (12.3 for the N86-184F haplotype versus $6.3 \mathrm{nM}$ for the N86Y184). This result is consistent with an in vitro study previously conducted in Senegal (Wurtz et al., 2014). Additionally, no mutations for the 1246 codon (1246Y) were found. This result 
supports the findings of in vivo studies that showed that the N86-184F-D1246 haplotype was present in artemether-lumefantrine reinfections in Senegal and East Africa (Mbaye et al., 2016; Otiennoburu et al., 2016).

In this study, no association was highlighted between N86 and 86Y alleles with in vitro susceptibility modulation to DQ. However, this result should be taken with caution due to the low frequency of the $86 \mathrm{Y}$ SNP. The data on the $86 \mathrm{Y}$ mutation and its involvement in DQ susceptibility are contradictory. Previous works showed no association between the haplotypes, N86 and 86Y, and DQ IC50 (Dahltröm et al., 2014), whereas other studies showed associations between 86Y mutation and increased (Wurtz et al., 2014) or decreased susceptibility to DQ (Folarin et al., 2011). The replacement by transfection of the $86 Y$ mutation by the wild-type N86 resulted in increased susceptibility to DQ (Veiga et al., 2016). Nevertheless, the $86 \mathrm{Y}$ mutation was found to be associated with treatment failures after amodiaquine monotherapy (Holmgren et al., 2006; Danquah et al., 2010) or artesunateamodiaquine (Venkatesan et al., 2014; Sondo et al., 2016; Yeka et al., 2016).

\section{Conclusion}

In summary, the present study showed the association between repetitive amino acid motifs (DNNN-DHHNDDHNNDNNN) in $p f m d r 5$ and in vitro susceptibility to 4-aminoquinoline based antimalarial drugs. In particular, parasites bearing 8 and more than 8 short motifs (DNNN) were more susceptible to piperaquine than isolates with less short motifs, and isolates with atypical long motif repeat (DHHNDDHNNDNNN) were more susceptible to pyronaridine, chloroquine and monodesethylamodiaquine. However, these results should be taken with caution due to the low frequency of the different alleles. The present results validated the association between the wild-type alleles N86 in pfmdrl and N86-184F haplotype with reduced susceptibility to lumefantrine. It will be important in future to analyze 
the potential association between piperaquine susceptibility modulation and $p f m d r 5$ and other genes which are involved in piperaquine resistance in Asia but not yet validated in African parasites, including plasmepsin 2-3, exonuclease or pfcrt genes (H97Y, F145I, M343L or G353V) (Amato et al., 2016; Witkowski et al., 2016; Agrawal et al, 2017; Ross et al., 2018). The multiple copies of the plasmepsin 2 gene, one of the most promising candidates, does not explain ex vivo or in vitro reduced susceptibility to piperaquine or clinical failure with dihydroartemisinin-piperaquine in Africa (Rasmussen et al., 2017; Inoue et al, 2018; Malvy et al., 2018; Robert et al., 2018; Robert et al., 2019; Russo et al., 2018). Further studies with a larger number of samples are required to validate the association between these $p f m d r 5$ alleles and modulation of antimalarial drug susceptibility.

\section{Ethics approval and consent to participate}

Verbal consent was obtained from all the patients or their parents/guardians before blood collection. Bio-banking of human clinical samples used for malaria diagnostics and secondary uses for scientific purposes is possible as long as the corresponding patients are informed and have not indicated any objections. This requirement was fulfilled here by giving verbal information to the patients, and no immediate or delayed patient opposition was reported to the hospital clinicians. The ethical committee of the Hôpital Principal de Dakar approved the study.

\section{Conflicts of interest}

The authors declare that they have no competing interests.

\section{Acknowledgements}


The authors thank the patients and the staff of the Hôpital Principal de Dakar, and Ndeye

Fatou Diop and Maurice Gomis from the Hôpital Principal de Dakar for technical support.

\section{Funding}

This work was supported by the Délégation Générale pour l'Armement [grant no PDH-2-

NRBC-4-B-4104]; the Schéma directeur Paludisme Etat Major des Armées Françaises [grant LR 607]; and by the Ministère des Affaires Etrangères. Francis T Foguim was supported by a scholarship from the Foundation Méditerranée Infection.

\section{References}

Agrawal, S., Moser, K.A., Morton, L., Cummings, M.P., Parihar, A., Dwivedi, A., Shetty, A.C., Drabek, E.F., Jacob, C.G., Henrich, P.P., Parotek, C.M., Jongsakul, K., Huy, R., Spring, M.D., Lanteri, C.A., Chaorattanakawee, S., Lon, C., Fukuda, M.M., Saunders, D.L., Fidoch, D.A., Lin, J.T., Juliano, J.J., Plowe, C.V., Silva, J.C., Takala-Harrison, S., 2017. Association of a novel mutation in the Plasmodium falciparum chloroquine transporter with decreased piperaquine sensitivity. J. Infect. Dis. 216, 468-476.

Amaratunga, C., Lim, P., Suon, S., Sreng, S., Mao, S., Sopha, C., Sam, B., Dek, D., Try, V., Amato, R., Blessborn, D., Song, L., Tullo, G.S., Fay, M.P., Anderson, J.M., Tarning, J., Fairhurst, R.M., 2016. Dihydroartemisinin-piperaquine resistance in Plasmodium falciparum malaria in Cambodia: a multisite prospective cohort study. Lancet Infect. Dis. $16,357-365$.

Amato, R., Lim, P., Miotto, O., Amaratunga, C., Dek, D., Pearson, R.D., Almagro-Garcia, J., Neal, A.T., Sreng, S., Suon, S., Drury, E., Jyothi, D., Stalker, J., Kwiatkowski, D.P., Fairhurst, R.M., 2016. Genetic markers associated with dihydroartemisinin-piperaquine 
failure in Plasmodium falciparum malaria in Cambodia: a genotype-phenotype association study. Lancet Infect. Dis. 17, 164-173.

Ashley, E.A., Dhorda, M., Fairhurst, R.M., Amaratunga, C., Lim, P., Suon, S., Sreng, S., Anderson, J.M., Mao, S., Sam, B., Sopha, C., Chuor, C.M., Nguon, C., Sovannaroth, S., Pukrittayakamee, S., Jittamala, P., Chotivanich, K., Chutasmit, K., Suchatsoonthorn, C., Runcharoen, R., Hien, T.T., Thuy-Nhien, N.T., Thanh, N.V., Phu, N.H., Htut, Y., Han, K.T., Aye, K.H., Mokuolu, O.A., Olaosebikan, R.R., Folaranmi, O.O., Mayxay, M., Khanthavong, M., Hongvanthong, B., Newton, P.N., Onyamboko, M.A., Fanello, C.I., Tshefu, A.K., Mishra, N., Valecha, N., Phyo, A.P., Nosten, F., Yi, P., Tripura, R., Borrmann, S., Bashraheil, M., Peshu, J., Faiz, M.A., Ghose, A., Hossain, M.A., Samad, R., Rahman, M.R., Hasan, M.M., Islam, A., Miotto, O., Amato, R., MacInnis, B., Stalker, J., Kwiatkowski, D.P., Bozdech, Z., Jeeyapant, A., Cheah, P.Y., Sakulthaew, T., Chalk, J., Intharabut, B., Silamut, K., Lee, S.J., Vihokhern, B., Kunasol, C., Imwong, M., Tarning, J., Taylor, W.J., Yeung, S., Woodrow, C.J., Flegg, J.A., Das, D., Smith, J., Venkatesan, M., Plowe, C.V., Stepniewska, K., Guerin, P.J., Dondorp, A.M., Day, N.P., White, N.J., 2014. Spread of artemisinin resistance in Plasmodium falciparum malaria. N. Engl. J. Med. 371, 411-423.

Baraka, V., Tinto, H., Valea, I., Fitzhenry, R., Delgado-Ratto, C., Mbonye, M.K., van Overmeir, C., Rosanas-Urgell, A., van geertruyden, J.P., D’Alessandro, U., Erhart, A., 2015. In vivo selection of Plasmodium falciparum Pfcrt and Pfmdrl variants by artemether-lumefantrine and dihydroartemisinin-piperaquine in Burkina Faso. Antimicrob. Agents Chemother. 59, 734-737.

Bogreau, H., Renaud, F., Bouchiba, H., Durand, P., Assi, S.B., Henry, M.C., Garnotel, H., Pradines, B., Fusai, T., Wade, B., Adehossi, E., Parola, P., Kamil, M.A., Puijalon, O., Rogier, C., 2006. Genetic diversity and structure of African Plasmodium falciparum populations in urban and rural areas. Am. J. Trop. Med. Hyg. 74, 953-959.

Dahlström, S., Aubouy, A., Maïga-Ascofaré, O., Faucher, J.F., Wakpo, A., Ezinmègnon, S., Massougbodji, A., Houzé, P., Kendjo, E., Deloron, P., Le Bras, J., Houzé, S., 2014. 
Plasmodium falciparum polymorphisms associated with ex vivo drug susceptibility and clinical effectiveness of artemisinin-based combination therapies in Benin. Antimicrob. Agents Chemother. 58, 1-10.

404

405

Danquah, I., Coulibaly, B., Meissner, P., Petruschke, I., Müller, O., Mockenhaupt, F.P., 2010. Selection of pfmdrl and pfcrt alleles in amodiaquine treatment failure in north-western Burkina Faso. Acta Trop. 114, 63-66.

Dokomajilar, C., Nsobya, S.L., Greenhouse, B., Rosenthal, P.J., Dorsey, G., 2006. Selection of Plasmodium falciparum pfmdrl alleles following therapy with artemether-lumefantrine in an area of Uganda where malaria is highly endemic. Antimicrob. Agents Chemother. 50, 1893-1895.

Dondorp, A.M., Nosten, F., Yi, P., Das, D., Phyo, A.P., Tarning, J., Lwin, K.M., Ariey, F., Hanpithakpong, W., Lee, S.J., Ringwald, P., Silamut, K., Imwong, M., Chotivanich, K., Lim, P., Herdman, T., An, S.S., Yeung, S., Singhasivanon, P., Day, N.P.J., Lindegardh, N., Socheat, D., White, N.J., 2009. Artemisinin resistance in Plasmodium falciparum malaria. N. Engl. J. Med. 361, 455-467.

Fall, B., Camara, C., Fall, M., Nakoulima, A., Dionne, P., Diatta, B., Diémé, Y., Wade, B., Pradines, B., 2015. Plasmodium falciparum susceptibility to standard and potential antimalarial drugs in Dakar, Senegal, during the 2013-2014 malaria season. Malar. J. 14, 60.

Fall, B., Diawara, S., Sow, K., Baret, E., Diatta, B., Fall, K.B., Mbaye, P.S., Fall, F., Diémé, Y., Rogier, C., Wade, B., Bercion, R., Pradines, B., 2011. Ex vivo susceptibility of Plasmodium falciparum isolates from Dakar, Senegal, to seven standard anti-malarial drugs. Malar. J. 10, 310.

Folarin, O.A., Bustamante, C., Gbotosho, G.O., Sowunmi, A., Zalis, M.G., Oduola, A.M., Happi, C.T., 2011. In vitro amodiaquine resistance and its association with 
mutations in $p f c r t$ and $p f m d r 1$ genes of Plasmodium falciparum isolates from Nigeria. Acta Trop. 120, 224-230.

427

428

Gendrot, M., Diawara, S., Madamet, M., Kounta, M.B., Briolant, S., Wade, K.A., Fall, M., Benoit, N., Nakoulima, A., Amalvict, R., Diémé, Y, Fall, B., Wade, B., Diatta, B., Pradines, B., 2017. Association between polymorphisms in the Pfmdr6 gene and ex vivo susceptibility to quinine in Plasmodium falciparum parasites from Dakar, Senegal. Antimicrob. Agents Chemother. 61, e01183-16.

Gendrot, M., Fall, B., Madamet, M., Fall, M., Wade, K.A., Amalvict, R., Nakoulima, A., Benoit, N., Diawara, S., Diémé, Y., Diatta, B., Wade, B., Pradines, B., 2016. Absence of association between polymorphisms in the RING E3 ubiquitin protein ligase gene and ex vivo susceptibility to conventional antimalarial drugs in Plasmodium falciparum isolates from Dakar, Senegal. Antimicrob. Agents Chemother. 60, 5010-5013.

Henry, M., Diallo, I., Bordes, J., Ka, S., Pradines, B., Diatta, B., M'Baye, P.S., Sane, M., Thiam M., Gueye, P.M., Wade, B., Touze, J.E., Debonne, J.M., Rogier, C., Fusai, T., 2006. Urban malaria in Dakar, Senegal: chemosusceptibility and genetic diversity of Plasmodium falciparum isolates. Am. J. Trop. Med. Hyg. 75, 146-151.

Holmgren, G., Gil, J.P., Ferreira, P.M., Veiga, M.I., Obonyo, C.O., Björkman, A., 2006. Amodiaquine resistant Plasmodium falciparum malaria in vivo is associated with selection of pfcrt 76T and pfmdr1 86Y. Infect. Genet. Evol. 6, 309-314.

Inoue, J., Silva, M., Fofana, B., Sanogo, K., Martensson, A., Sagara, I., Björkman, A., Veiga, M.I., Ferreira, P.E., Djimde, A., Gil, J.P., 2018. Plasmodium falciparum plasmepsin 2 duplications, West Africa. Emerg. Infect. Dis. 24, 1591-1593.

Kavishe, R.A., van den Heuvel, J.M.W., van de Vegte-Bolmer, M., Luty, A.J.F., Russel, F.G.M., Koenderink, J.B., 2009. Localization of the ATP-binding cassette (ABC) transport 
proteins PfMRP1, PfMRP2, and PfMDR5 at the Plasmodium falciparum plasma membrane. Malar. J. 8, 205.

451

452

453

454

455

456

457

458

459

460

461

462

463

464

Leang, R., Taylor, W.R.J., Bouth, D.M., Song, L., Tarning, J., Char, M.C., Kim, S., Witkowski, B., Duru, V., Domergue, A., Khim, N., Ringwald, P., Menard, D., 2015. Evidence of Plasmodium falciparum malaria multidrug resistance to artemisinin and piperaquine in Western Cambodia: Dihydroartemisinin-piperaquine open-label multicenter clinical assessment. Antimicrob. Agents Chemother. 59, 4719-4726.

Malvy, D., Torrentino-Madamet, M., L'Ollivier, C., Receveur, M.C., Jeddi, F., Delhaes, L., Piarroux, R., Millet, P., Pradines, B., 2018. Plasmodium falciparum recrudescence two years after treatment of an uncomplicated infection without return to an area where malaria is endemic. Antimicrob. Agents Chemother. 62, e01892-17.

Mbaye, A., Dieye, B., Ndiaye, Y.D., Bei, A.K., Muna, A., Deme, A.B., Yade, M.S., Diongue, K., Gaye, A., Ndiaye, I.M., Ndiaye, T., Sy, M., Diallo, M.A., Badiane, A.S., Ndiaye, M., Seck, M.C., Sy, N., Koita, O., Krogstad, D.J., Nwakanma, D., Ndiaye, D., 2016. Selection of N86F184D1246 haplotype of Pfmrdl gene by artemether-lumefantrine drug pressure on Plasmodium falciparum populations in Senegal. Malar. J. 15, 433.

Ménard, D., Khim, N., Beghain, J., Adegnika, A.A., Alam, M.S., Amodu, O., Awab, G.R., Barnadas, C., Berry, A., Boum, Y., Bustos, M.D., Cao, J., Chen, J.H., Collet, L., Cui, L., Das Thakur, G., Dieye, A., Djalle, D., Dorkenoo, M.A., Eboumbou Moukoko, C.E., Espino, E., Fandeur, T., Ferreira-Da-Cruz, M.F., Fola, A.A., Fuehrer, H.P., Hassan, A.M., Herrera, S., Hongvanthong, B., Houze, S., Karim, M.J., Jiang, L., Kano, S., Khan, W.A., Khanthavong, M., Kremsner, P.G., Lacerda, M., Leang, R., Leelawong, M., Li, M., Lin, K., Laminou, I.M., Mazarati, J.B., Menard, S., Morlais, I., Muhindo Mavoko, H., Musset, L., Na-Bangchang, K., Nambozi, M., Niare, K., Noedl, H., Ouedraogo, J.B., Pillai, D.R., Pradines, B., Quang Phuc, B., Ramharter, M., Randrianarivelojosia, M., Sattabongkot, J., 
Sheikh Omar, R., Silue, K.D., Sirima, S.B., Sutherland, C., Syafruddin, D., Tahar, R., Tang, L.H., Toure, O.A., Tshibangu, P., Vigan-Womas, I., Warsame, M., Wini, L., Zakeri, S., Kim, S., Eam, R., Berne, L., Khean, C., Chy, S., Ken, M., Loch, K., Canier, L., Duru, V., Legrand, E., Barale, J.C., Stokes, B., Straimer, J., Witkowski, B., Fidock, D.A., Rogier, C., Ringwald, P., Ariey, F., Mercereau-Puijalon, O .; for the K13 Artemisinin Resistance Multicenter Assessment consortium (KARMA), 2016. A worldwide map of Plasmodium falciparum K13-propeller polymorphisms. N. Engl J. Med. 374, 2453-2464.

Mita, T., Venkatesan, M., Ohashi, J., Culleton, R., Takahashi, N., Tsukahara, T., Ndounga, M., Dysoley, L., Endo, H., Hombhanje, F., Ferreira, M.U., Plowe, C.V., Tanabe, K., 2011. Limited geographical origin and global spread of sulfadoxine-resistant dhps alleles in Plasmodium falciparum populations. J. Infect. Dis. 204, 1980-1988.

Mungthin, M., Khositnithikul, R., Sitthichot, N., Suwandittakul, N., Wattanaveeradej, V., Ward, S.A., Na-Bangchang, K., 2010. Association between the pfmdrl gene and in vitro artemether and lumefantrine sensitivity in Thai isolates of Plasmodium falciparum. Am. J. Trop. Med. Hyg. 83, 1005-1009.

Mwai, L., Kiara, S.M., Abdirahman, A., Pole, L., Rippert, A., Diriye, A., Bull, P., Marsh, K., Borrmann, S., Nzila, A., 2009. In vitro activities of piperaquine, lumefantrine, and dihydroartemisinin in Kenyan Plasmodium falciparum isolates and polymorphisms in pfcrt and pfmdrl. Antimicrob. Agents Chemother. 53, 5069-5073.

Nankabirwa, J.I., Conrad, M.D., Legac, J., Tukwasibwe, S., Tumwebaze, P., Wandera, B., Brooker, S. J., Staedke, S.G., Kamya, M.R., Nsobya, S.L., Dorsey, G., Rosenthal, P.J., 2016. Intermittent preventive treatment with dihydroartemisinin-piperaquine in Ugandan schoolchildren selects for Plasmodium falciparum transporter polymorphisms that modify drug sensitivity. Antimicrob. Agents Chemother. 60, 5649-5654. 
Okombo, J., Abdi, A.I., Kiara, S.M., Mwai, L., Pole, L., Sutherland, C.J., Nzila, A., OcholaOyier, L.I., 2013. Repeat polymorphisms in the low-complexity regions of Plasmodium falciparum $\mathrm{ABC}$ transporters and associations with in vitro antimalarial responses. Antimicrob. Agents Chemother. 57, 6196-6204.

Otienoburu, S.D., Maïga-Ascofaré, O., Schramm, B., Jullien, V., Jones, J.J., Zolia, Y.M., Houzé, P., Ashley, E.A., Kiechel, J.R., Guérin, P.J., Le Bras, J., Houzé, S., 2016. Selection of Plasmodium falciparum pfcrt and pfmdrl polymorphisms after treatment with artesunate-amodiaquine fixed dose combination or artemether-lumefantrine in Liberia. Malar. J. 15, 452.

Parobek, C. M., Parr, J.B., Brazeau, N.F., Lon, C., Chaorattanakawee, S., Gosi, P., Barnett, E.J., Norris, L.D., Meshnick, S.R., Spring, M.D., Lanteri, C.A., Bailey, J.A., Saunders, D.L., Lin, J.T., Juliano, J.J., 2017. Partner-drug resistance and population substructuring of artemisinin-resistant Plasmodium falciparum in Cambodia. Genome Biol. Evol. 9, 16731686.

Pascual, A., Madamet, M., Briolant, S., Gaillard, T., Amalvict, R., Benoit, N., Travers, D., Pradines, B., 2015. Multinormal in vitro distribution of Plasmodium falciparum susceptibility to piperaquine and pyronaridine. Malar. J. 14, 49.

Phuc, B.Q., Rasmussen, C., Duong, T.T., Dong, L.T., Loi, M.A., Ménard, D., Tarning, J., Bustos, D., Ringwald, P., Galappaththy, G.L., Thieu, N.Q., 2017. Treatment failure of dihydroartemisinin/piperaquine for Plasmodium falciparum malaria, Vietnam. Emerg. Infect. Dis. 23, 715-717.

Pillai, D.R., Lau, R., Khairnar, K., Lepore, R., Via, A., Staines, H.M., Krishna, S., 2012. Artemether resistance in vitro is linked to mutations in PfATP6 that also interact with mutations in PfMDR1 in travellers returning with Plasmodium falciparum infections. Malar. J. 11, 131. 
Pradines, B., Pagès, J.M., Barbe, J., 2005. Chemosensitizers in drug transport mechanisms involved in protozoan resistance. Curr. Drug Targets Infect. Disord. 5, 411-431.

Pradines, B., Parquet, V., Orlandi-Pradines, E., 2009. ABC transporters in Plasmodium and their involvement in resistance to antimalarial drugs, in: Ponte-Sucre, A. (ed), ABC Transporters in Microorganisms. Caister Academic Press, Wymondham, UK, pp 113-128.

Price, R.N., Uhlemann, A.C., Brockman, A., McGready, R., Ashley, E., Phaipun, L., Patel, R., Looareesuwan, S., White, N.J., Nosten, F., Krishna, S., 2004. Mefloquine resistance in Plasmodium falciparum and increased pfmdrl gene copy number. Lancet 364, 438-447.

Rasmussen, S.A., Ceja, F.G., Conrad, M.D., Tumwebaze, P.K., Byaruhanga, O., Katairo, T., Nsobya, S.L., Rosenthal, P.J., Cooper, R.A., 2017. Changing antimalarial drug sensitivities in Uganda. Antimicrob. Agents Chemother. 61, e01516-17.

Robert, M.G., Foguim Tsombeng, F., Gendrot, M., Diawara, S., Madamet, M., Kounta, M.B., Wade, K.A., Fall, M., Gueye, M.W., Benoit, N., Nakoulima, A., Bercion, R., Amalvict, R., Fall, B., Wade, B., Diatta, B., Pradines, B., 2019. Baseline ex vivo and molecular responses of Plasmodium falciparum isolates to piperaquine before implementation of dihydroartemisinin-piperaquine in Senegal. Antimicrob. Agents Chemother. 63, e0244818.

Robert, M.G., Foguim Tsombeng, F., Gendrot, M., Mosnier, J., Amalvict, R., Benoit, N., Torrentino-Madamet, M., Pradines, B., the French National Reference Centre for imported Malaria Study Group., 2018. Absence of high level of duplication of the plasmepsin 2 gene in Africa. Antimicrob. Agents Chemother. 62, e00374-18.

Ross, L.S., Dhingra, S.K., Mok, S., Yeo, T., Wicht, K.J., Kümpornsin, K., Takala-Harrison, S., Witkowski, B., Fairhurst, R.M., Ariey, F., Ménard, D., Fidock, D.A., 2018. Emerging Southeast Asian Pfcrt mutations confer Plasmodium falciparum resistance to the first-line antimalarial piperaquine. Nat. Commun. 9, 3314. 
Russo G, L'Episcopia M, Menegon M, Souza SS, Dongho BGD, Vullo V, Lucchi NW, Severini C. 2018. Dihydroartemisinin-piperaquine treatment failure in uncomplicated Plasmodium falciparum malaria case imported from Ethiopia. Infection 2018 Jul 6. doi: $10.1007 / \mathrm{s} 15010-018-1174-9$

Sidhu, A.B., Valderramos, S.G., Fidock, D.A., 2005. Pfmdrl mutations contribute to quinine resistance and enhance mefloquine and artemisinin sensitivity in Plasmodium falciparum. Mol. Microbiol. 57, 913-926.

Sisowath, C., Stromberg, J., Martensson, A., Msellem, M., Obondo, C., Björkman, A., Gil, J.P., 2005. In vivo selection of Plasmodium falciparum pfmdr1 86N coding alleles by artemether-lumefantrine (Coartem). J. Infect. Dis. 191, 1014-1017.

Sondo, P., Derra, K., Diallo Nakanabo, S., Tarnagda, Z., Kazienga, A., Zampa, O., Valéa, I., Sorgho, H., Owusu-Dabo, E., Ouédraogo, J.B., Guiguemdé, T.R., Tinto, H., 2016. Artesunate-amodiaquine and artemether-lumefantrine therapies and selection of Pfcrt and Pfmdrlalleles in Nanoro, Burkina Faso. PLoS One 11, e0151565.

Spring, M.D., Lin, J.T., Manning, J.E., Vanachayangkul, P., Somethy, S., Bun, R., Se, Y., Chann, S., Ittiverakul, M., Sia-Ngam, P., Kuntawunginn, W., Arsanok, M., Buathong, N., Chaorattanakawee, S., Gosi, P., Ta-Aksorn, W., Chanarat, N., Sundrakes, S., Kong, N., Heng, T.K., Nou, S., Teja-Isavadharm, P., Pichyangkul, S., Phann, S.T., Balasubramanian, S., Juliano, J.J., Meshnick, S.R., Chour, C.M., Prom, S., Lanteri, C.A., Lon, C., Saunders, D.L., 2015. Dihydroartemisinin-piperaquine failure associated with a triple mutant including kelch13 C580Y in Cambodia: an observational cohort study. Lancet Infect. Dis. $15,683-691$.

Taylor, A.R., Flegg, J.A., Holmes, C.C., Guérin, P.J., Sibley, C.H., Conrad, M.D., Dorsey, G., Rosenthal, P.J., 2016. Artemether-lumefantrine and dihydroartemisinin-piperaquine exert 
inverse selective pressure on Plasmodium falciparum drug sensitivity-associated haplotypes in Uganda. Open Forum Infect. Dis. 4, ofw229.

574

575

Thanh, N.V., Thuy-Nhien, N., Tuyen, N.T., Tong, N.T., Nha-Ca, N.T., Dong, L.T., Quang, H.H., Farrar, J., Thwaites, G., White, N.J., Wolbers, M., Hien, T.T., 2017. Rapid decline in the susceptibility of Plasmodium falciparum to dihydroartemisinin-piperaquine in the south of Vietnam. Malar. J. 16, 27.

Van der Velden, M., Rijpma, S.R., Russel, F.G.M., Sauerwein, R.W., Koenderink, J.B., 2015. PfMDR2 and PfMDR5 are dispensable for Plasmodium falciparum asexual parasite multiplication but change in vitro susceptibility to anti-malarial drugs. Malar. J. 14, 76.

Veiga, M.I., Dhingra, S.K., Henrich, P.P., Straimer, J., Gnägig, N., Uhlemann, A.C., Martin, R.E., Lehane, A.M., Fidock, D.A., 2016. Globally prevalent PfMDR1 mutations modulate Plasmodium falciparum susceptibility to artemisinin-based combination therapies. Nature Commun. 7, 11553.

Veiga, M.I., Osorio, N.S., Ferreira, P.E., Franzen, O., Dahlstrom, S., Lum, J.K., Nosten, F., Gil, J.P., 2014. Complex polymorphisms in the Plasmodium falciparum multidrug resistance protein 2 gene and its contribution to antimalarial response. Antimicrob. Agents Chemother. 58, 7390-7397.

Venkatesan, M., Gadalla, N.B., Stepniewska, K., Dahal, P., Nsanzabana, C., Moriera, C., Price, R.N., Martensson, A., Rosenthal, P.J., Dorsey, G., Sutherland, C.J., Guérin, P., Davis, T.M.E., Ménard, D., Adam, I., Ademowo, G., Arze, C., Baliraine, F.N., BerensRiha, N., Björkman, A., Borrmann, S., Checchi, F., Desai, M., Dhorba, M., Djimdé, A.A., El-Sayed, B.B., Eshetu, T., Eyase, F., Falade, C., Faucher, J.F., Fröberg, G., Grivoyannis, A., Hamour, S., Houzé, S., Jonson, J., Kamugisha, E., Kariuki, S., Kiechel, J.R., Kironde, F., Kofoed, P.E., Le Bras, J., Malmberg, M., Mwai, L., Ngasala, B., Nosten, F., Nsobya, S.L., Nzila, A., Oguike, M., Dahlström Otiennoburu, S., Ogutu, B., Ouédraogo, J.B., Piola, 

P., Rombo, L., Schramm, B., Somé, A.F., Thwing, J., Ursing, J., Wong, R.P.M., Zeynudin, A., Zongo, I., Plowe, C.V., Hopkins Sibley, C., 2014. Polymorphisms in Plasmodium falciparum chloroquine resistance transporter and multidrug resistance 1 genes: parasite risk factors that affect treatment outcomes for $P$. falciparum malaria after artemetherlumefantrine and artesunate-amodiaquine. Am. J. Trop. Med. Hyg. 91, 833-843.

Wang, Z., Parker, D., Meng, H., Wu, L., Li, J., Zhao, Z., Zhang, R., Fan, Q., Wang, H., Cui, L., Yang, Z., 2012. In vitro sensitivity of Plasmodium falciparum from China-Myanmar border area to major ACT drugs and polymorphisms in potential target genes. PLoS One 7, 30927.

Witkowski, B., Duru, V., Khim, N., Ross, L.S., Saintpierre, B., Beghain, J., Chy, S., Kim, S., Ke, S., Kloeung, N., Eam, R., Khean, C., Ken, M., Loch, K., Bouillon, A., Domergue, A., Ma, L., Bouchier, C., Leang, R., Huy, R., Nuel, G., Barale, J.C., Legrand, E., Ringwald, P., Fidock, D.A., Mercereau-Puijalon, O., Ariey, F., Ménard, D., 2016. A surrogate marker of piperaquine-resistant Plasmodium falciparum malaria: a phenotype-genotype association study. Lancet Infect. Dis. $17,174-183$.

Wootton, J.C., Feng, X., Ferdig, M.T., Cooper, R.A., Mu, J., Baruch, D.I., Magill, A.J., Su, X.Z., 2002. Genetic diversity and chloroquine selective sweeps in Plasmodium falciparum. Nature 418, 320-323.

Wurtz, N., Fall, B., Pascual, A., Fall, M., Baret, E., Camara, C., Nakoulima, A., Diatta, B., Fall, K.B., Mbaye, P.S., Diémé, Y., Bercion, R., Wade, B., Pradines, B., 2014. Role of Pfmdrl in in vitro susceptibility to chloroquine, quinine, monodesethylamodiaquine, mefloquine, lumefantrine and dihydroartemisinin. Antimicrob. Agents Chemother. 58, 7032-7040.

Yeka, A., Kigozi, R., Conrad, M.D., Lugemwa, M., Okui, P., Katureebe, C., Belay, K., Kapella, B.K., Chang, M.A., Kamya, M.R., Staedke, S.G., Dorsey, G., Rosenthal, P.J., 
622 2016. Artesunate/amodiaquine versus artemether/lumefantrine for the treatment of

623 uncomplicated malaria in Uganda: A randomized trial. J. Infect. Dis. 213:1134-1142.

624

625 
627 Forward and reverse primers, hybridization temperature (Tm) and $\mathrm{MgCl}_{2}$ concentration used 628 for PCR

629

\begin{tabular}{|c|c|c|c|}
\hline Gene & Forward and Reverse primers & Tm & {$\left[\mathrm{MgCl}_{2}\right]$} \\
\hline $\begin{array}{l}\text { pfmdr5 } \\
\text { (PF3D7_1339900) }\end{array}$ & $\begin{array}{l}\text { Pfmdr5-F } \\
\text { 5'-CAAAAAGTGAAACGCAAACG-3' } \\
\text { Pfmdr5-R } \\
\text { 5'-GAGGATCTTCATCTTGTGTTCG-3' }\end{array}$ & $52^{\circ} \mathrm{C}$ & $2.5 \mathrm{mM}$ \\
\hline $\begin{array}{l}\text { pfmdrl } \\
\text { (PF3D7_0523000) }\end{array}$ & $\begin{array}{l}\text { MDR1-2F } \\
\text { 5'-CAG GAA GCA TTT TAT AAT ATG CAT-3' } \\
\text { MDR1-2R } \\
\text { 5'-CGT TTA ACA TCT TCC AAT GTT GCA-3' }\end{array}$ & $52^{\circ} \mathrm{C}$ & $2.5 \mathrm{mM}$ \\
\hline
\end{tabular}


633 Distribution of the average parameters of P. falciparum susceptibility to chloroquine (CQ),

634 quinine (QN), monodesethylamodiaquine (DQ), lumefantrine (LMF), mefloquine (MQ),

635 piperaquine (PPQ), pyronaridine (PND) and dihydroartemisinin (DHA)

636

\begin{tabular}{|c|c|c|c|c|c|c|c|}
\hline Drugs & Quartile 1 & Median & Quartile 3 & Mean & Standard error & Cut off ${ }^{1}$ & $\begin{array}{l}\text { Reduced } \\
\text { susceptibility } \\
(\%)^{2}\end{array}$ \\
\hline CQ & 26.2 & 85.7 & 154.8 & 112.9 & 14.6 & 77 & 46.3 \\
\hline QN & 54.6 & 138.3 & 286.0 & 221.2 & 29.0 & 611 & 9.2 \\
\hline DQ & 8.1 & 21.0 & 50.3 & 38.6 & 5.1 & 61 & 22.4 \\
\hline LMF & 1.7 & 4.7 & 12.5 & 9.8 & 1.5 & 115 & 0 \\
\hline MQ & 13.8 & 29.3 & 46.1 & 35.4 & 3.2 & 30 & 49.2 \\
\hline PPQ & 23.6 & 48.4 & 69.3 & 54.4 & 5.2 & 135 & 6.6 \\
\hline PND & 5.6 & 11.3 & 17.3 & 14.1 & 1.9 & 60 & 3.5 \\
\hline DHA & 0.7 & 1.8 & 4.3 & 2.9 & 0.4 & 12 & 1.7 \\
\hline
\end{tabular}

637

${ }^{1}$ The threshold values for the reduced in vitro susceptibility or resistance were previously

638 estimated (Fall et al., 2011; Pascual et al., 2015).

$639{ }^{2}$ This column showed the proportion of isolates with $\mathrm{IC}_{50}$ above the threshold value. 
Table 3

642 Association between the $p f m d r 5$ genotypes analyzed among the 67 clinical isolates from

643 Dakar, Senegal and ex vivo susceptibility to chloroquine (CQ), quinine (QN),

644 monodesethylamodiaquine (DQ), lumefantrine (LMF), mefloquine (MQ), piperaquine (PPQ),

645 pyronaridine (PND) and dihydroartemisinin (DHA)

646

\begin{tabular}{|c|c|c|c|c|c|c|c|c|c|c|}
\hline \multirow[t]{2}{*}{ Allele $^{\mathrm{a}}$} & \multirow[t]{2}{*}{$\mathrm{No}^{\mathrm{b}}$} & \multirow[t]{2}{*}{$\begin{array}{l}\text { Frequency } \\
(\%)\end{array}$} & \multicolumn{8}{|c|}{$\begin{array}{l}\mathrm{IC}_{50} \text { mean in } \mathrm{nM} \text { for parasites bearing these genotypes versus } \mathrm{IC}_{50} \text { mean in } \mathrm{nM} \text { of } \\
\text { those that do not ( } \mathbf{p} \text { is displayed only when } \mathbf{p}<\mathbf{0 . 0 5})^{\mathrm{c}}\end{array}$} \\
\hline & & & CQ & QN & DQ & LMF & MQ & PPQ & PND & DHA \\
\hline $5-1$ & 17 & 25.5 & $106.6 / 115.4$ & $350.0 / 196.2$ & $31.5 / 40.3$ & $5.1 / 8.0$ & $39.1 / 34.9$ & $57.1 / 51.0$ & $16.7 / 13.9$ & $3.3 / 2.8$ \\
\hline 6-1 & 16 & 23.9 & $122.8 / 110.1$ & $187.2 / 251.3$ & $37.6 / 38.2$ & $10.5 / 6.2$ & $36.5 / 36.0$ & $58.5 / 51.0$ & $23.6 / 12.0$ & $3.0 / 2.5$ \\
\hline $7-1$ & 13 & 19.1 & $180.6 / 96.9$ & $229 / 238$ & $54.7 / 34.0$ & $7.7 / 7.2$ & $44.4 / 34.4$ & $55.0 / 52.2$ & $11.5 / 15.3$ & $1.9 / 2.8$ \\
\hline $8-1$ & 6 & 9.0 & 97.0/114.7 & $209.7 / 239.0$ & $42.7 / 37.6$ & $9.5 / 7.1$ & $33.9 / 36.2$ & $\begin{array}{l}30.6 / 54.3 \\
(0.042)\end{array}$ & $9.3 / 15.0$ & $2.8 / 2.6$ \\
\hline $3-0$ & 3 & 4.5 & $\begin{array}{l}30.8 / 117.0 \\
(<0.001)\end{array}$ & $197 / 238$ & $\begin{array}{l}10.7 / 39.3 \\
(<0.001)\end{array}$ & $3.6 / 7.5$ & $\begin{array}{l}18.5 / 37.0 \\
(0.021)\end{array}$ & $50.8 / 52.8$ & $\begin{array}{l}5.1 / 15.2 \\
(<0.001)\end{array}$ & $1.4 / 2.7$ \\
\hline $3 / 7 / 8-0^{\mathrm{d}}$ & 5 & 7.5 & $\begin{array}{l}28.2 / 120.0 \\
(<0.001)\end{array}$ & $191.9 / 240.0$ & $\begin{array}{l}8.3 / 40.4 \\
(<0.001)\end{array}$ & $\begin{array}{l}2.4 / 7.7 \\
(0.037)\end{array}$ & $24.8 / 37.0$ & $77.8 / 50.5$ & $\begin{array}{l}6.0 / 15.5 \\
(<0.001)\end{array}$ & $1.7 / 2.7$ \\
\hline$\geq 8-\mathrm{x}^{\mathrm{e}}$ & 11 & 16.5 & $40.1 / 60.0$ & $70.4 / 129.3$ & $15.8 / 20.7$ & $5.5 / 3.5$ & $13.7 / 27.8$ & $\begin{array}{l}14.0 / 40.6 \\
(0.003)\end{array}$ & $\begin{array}{l}2.7 / 10.5 \\
(0.04)\end{array}$ & $0.9 / 1.4$ \\
\hline $2-2$ & 1 & 1.5 & & & & & & & & \\
\hline $3-1$ & 1 & 1.5 & & & & & & & & \\
\hline $3-2$ & 1 & 1.5 & & & & & & & & \\
\hline $4-1$ & 2 & 3.0 & & & & & & & & \\
\hline $5-2$ & 1 & 1.5 & & & & & & & & \\
\hline $7-0$ & 1 & 1.5 & & & & & & & & \\
\hline $8-0$ & 1 & 1.5 & & & & & & & & \\
\hline $9-1$ & 2 & 3.0 & & & & & & & & \\
\hline $11-1$ & 2 & 3.0 & & & & & & & & \\
\hline
\end{tabular}

647

${ }^{\mathrm{a}}$ Number of DNNN motifs followed by number of DHHNDHNNDNNN units

$648{ }^{\mathrm{b}}$ Number of samples bearing each genotype. 
$649{ }^{\mathrm{c}}$ Statistical analysis used Welsh two-sample t test to compare $\mathrm{IC}_{50}$ for parasites bearing these 650 genotypes versus those that do not have, and significant results $(\mathrm{p}<0.05)$ are in bold. The 651 analysis was only done for genotypes with number of samples for each genotype $>3$.

$652{ }^{\mathrm{d}}$ All the parasites without a DHHNDHNNDNNN motif were compared with all others.

$653{ }^{\mathrm{e}}$ All the parasites with a number of DNNN motif $\geq 8$ were compared with all others.

654

655 


\section{Table 4}

657 Association between the $p f m d r l$ genotypes analyzed among the 67 clinical isolates from

658 Dakar, Senegal and ex vivo susceptibility to chloroquine (CQ), quinine (QN),

659 monodesethylamodiaquine (DQ), lumefantrine (LMF), mefloquine (MQ), piperaquine (PPQ),

660 pyronaridine (PND) and dihydroartemisinin (DHA)

661

\begin{tabular}{|c|c|c|c|c|c|c|c|c|c|}
\hline \multirow{3}{*}{$\begin{array}{l}\text { Pfmdrl } \\
\text { Genotypes }\end{array}$} & \multirow[t]{3}{*}{$\mathrm{No}^{\mathrm{a}}$} & \multicolumn{8}{|c|}{$\mathrm{IC}_{50}$ mean in $\mathrm{nM}$ for parasites bearing the first genotype versus $\mathrm{IC}_{50}$ mean in $\mathrm{nM}$ of those } \\
\hline & & \multicolumn{8}{|c|}{ bearing the second ( $\mathrm{p}$ is displayed only when $\mathrm{p}<0.05$ ) } \\
\hline & & CQ & QN & DQ & LMF & MQ & PPQ & PND & DHA \\
\hline $\mathrm{N} 86 / 86 \mathrm{Y}$ & $73 / 4$ & $117.7 / 85.8$ & $226.6 / 190$ & $40.5 / 34.5$ & $\begin{array}{l}9.9 / 2.1 \\
(0.002)\end{array}$ & $36.6 / 30.6$ & $53.8 / 81.3$ & $13 / 40.3$ & $2.7 / 6.5$ \\
\hline $184 / 184 \mathrm{~F}$ & $31 / 44$ & $111.3 / 116$ & 227/223 & $38.2 / 39.4$ & $6.2 / 11.6$ & $42.4 / 31.8$ & $57.5 / 54$ & $13.3 / 15.6$ & $2.6 / 3.2$ \\
\hline N86-Y184 & $30 / 42$ & $113.6 / 119$ & $229 / 229$ & $39.1 / 42$ & $6.4 / 12.4$ & $43 / 31.8$ & $58.4 / 50$ & $12.5 / 13.3$ & $2.6 / 2.8$ \\
\hline /N86-184F & & & & & $(\mathbf{0 . 0 4 9})$ & & & & \\
\hline
\end{tabular}

$662{ }^{a}$ Number of samples bearing each genotype; WT/Mutated

$663 \mathrm{~b}^{\mathrm{b}}$ Statistical analysis used Welsh two-sample $\mathrm{t}$ test to compare $\mathrm{IC}_{50}$ for parasites bearing these

664 genotypes versus those bearing another, and significant results $(\mathrm{p} \leq 0.05)$ are in bold.

665

666 
667 Fig. 1. Distribution of ex vivo responses of 67 P. falciparum clinical field isolates from Dakar,

668 Senegal to piperaquine (PPQ), monodesethylamodiaquine (DQ), mefloquine (MQ),

669 pyronaridine (PND), chloroquine (CQ), quinine (QN), dihydroartemisinin (DHA) and

670 lumefantrine (LMF).

671

672 Fig. 2. (A) Association between allele 8-1 of $p f m d r 5$ and increased susceptibility to

673 piperaquine (PPQ) (30.6 versus $54.3 \mathrm{nM}$; $\mathrm{p}=0.042$; Welch two-sample $t$ test) and (B) between

674 alleles with 8 and more than 8 motif repeats $(\geq 8-x)$ and increased susceptibility to PPQ (14.0

675 versus $40.6 \mathrm{nM})$.

676

677 Fig. 3. Association between the $p f m d r 1$ N86-184F haplotype and decreased susceptibility to 678 lumefantrine (LMF).

679

680 Fig. 4. Association between the pfmdr1 N86Y and Y184F alleles with susceptibility to

681 lumefantrine (LMF) (12.3 versus $6.3 \mathrm{nM} ; \mathrm{p}=0.049)$. 

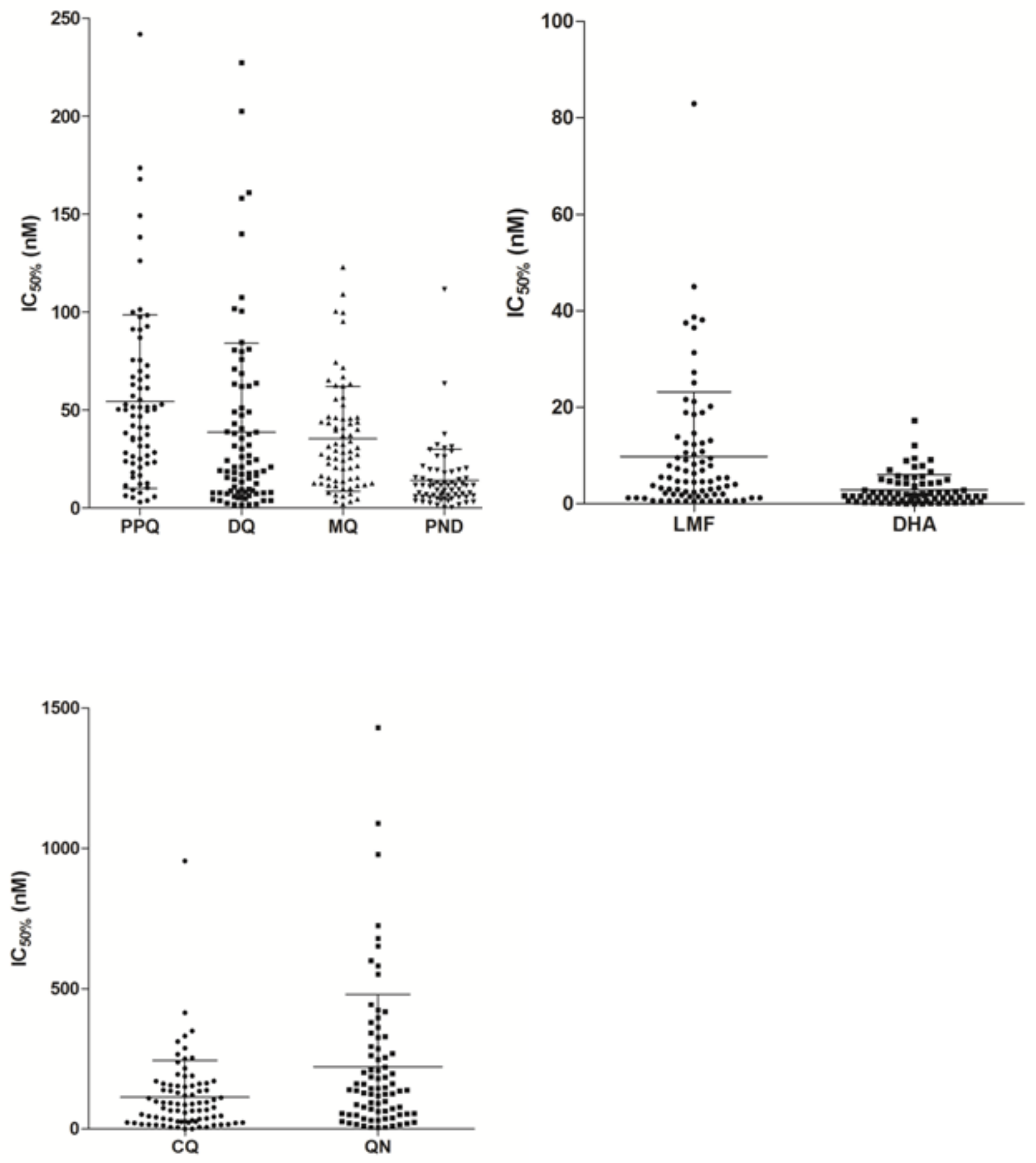

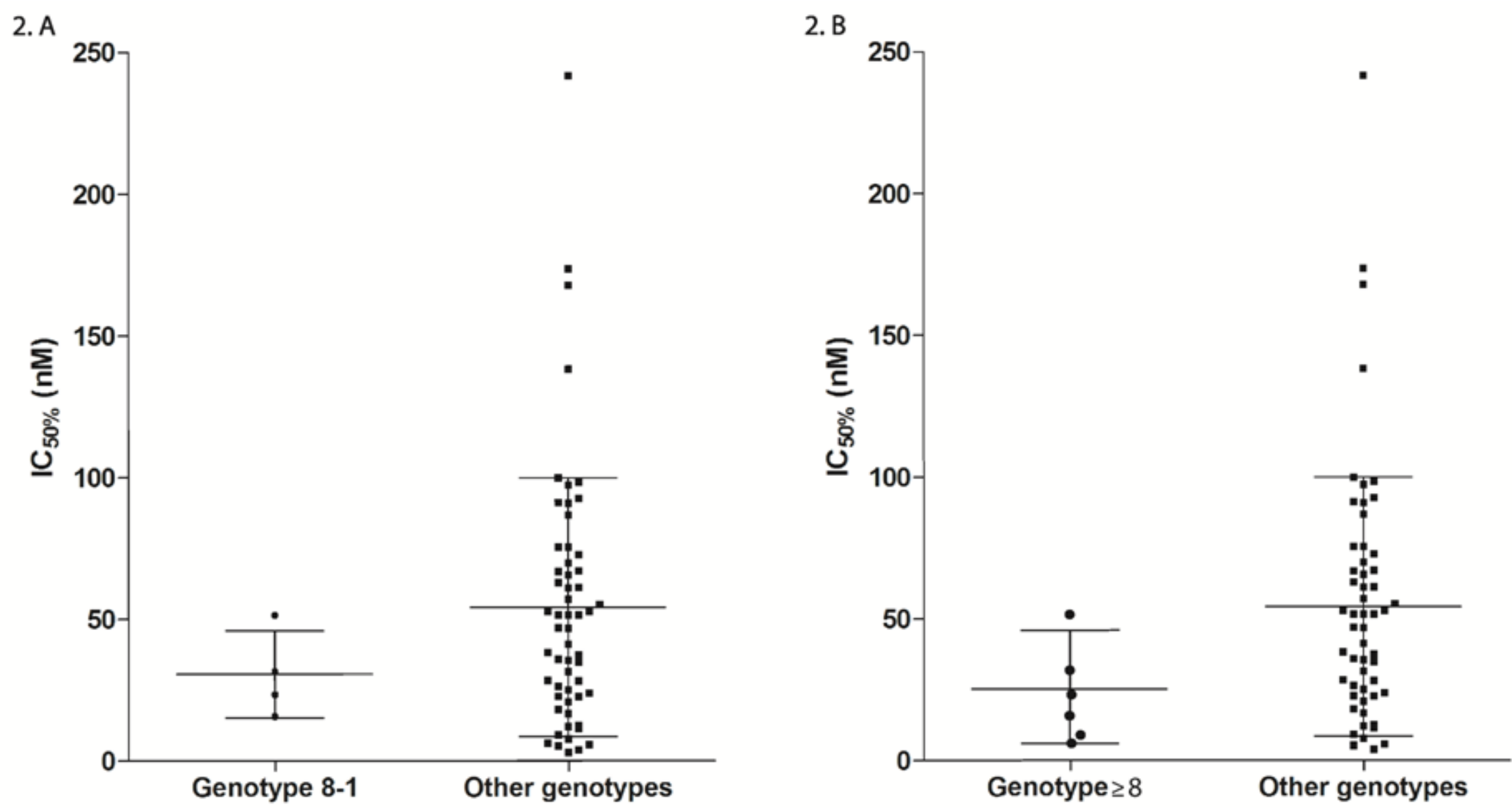

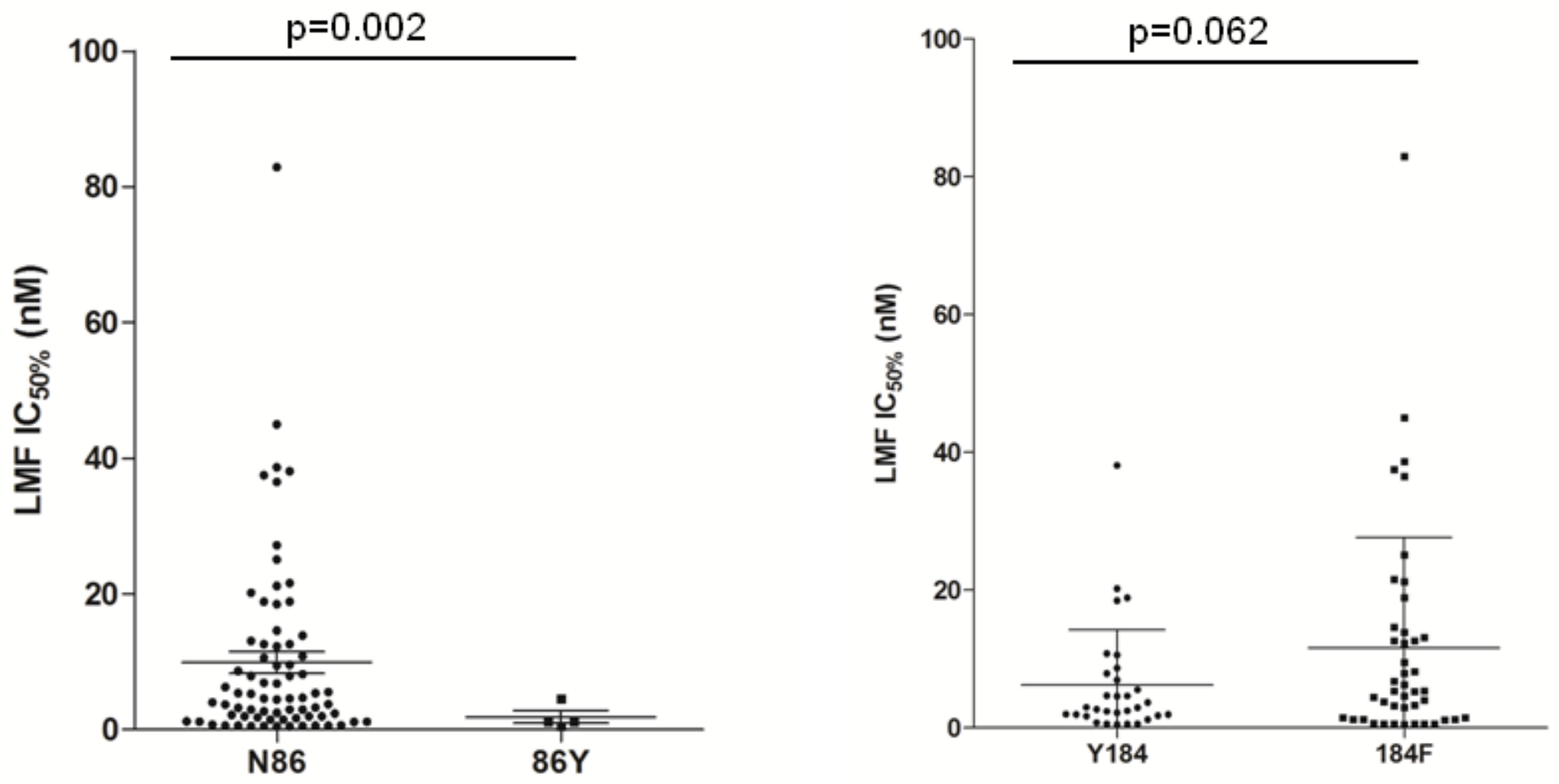


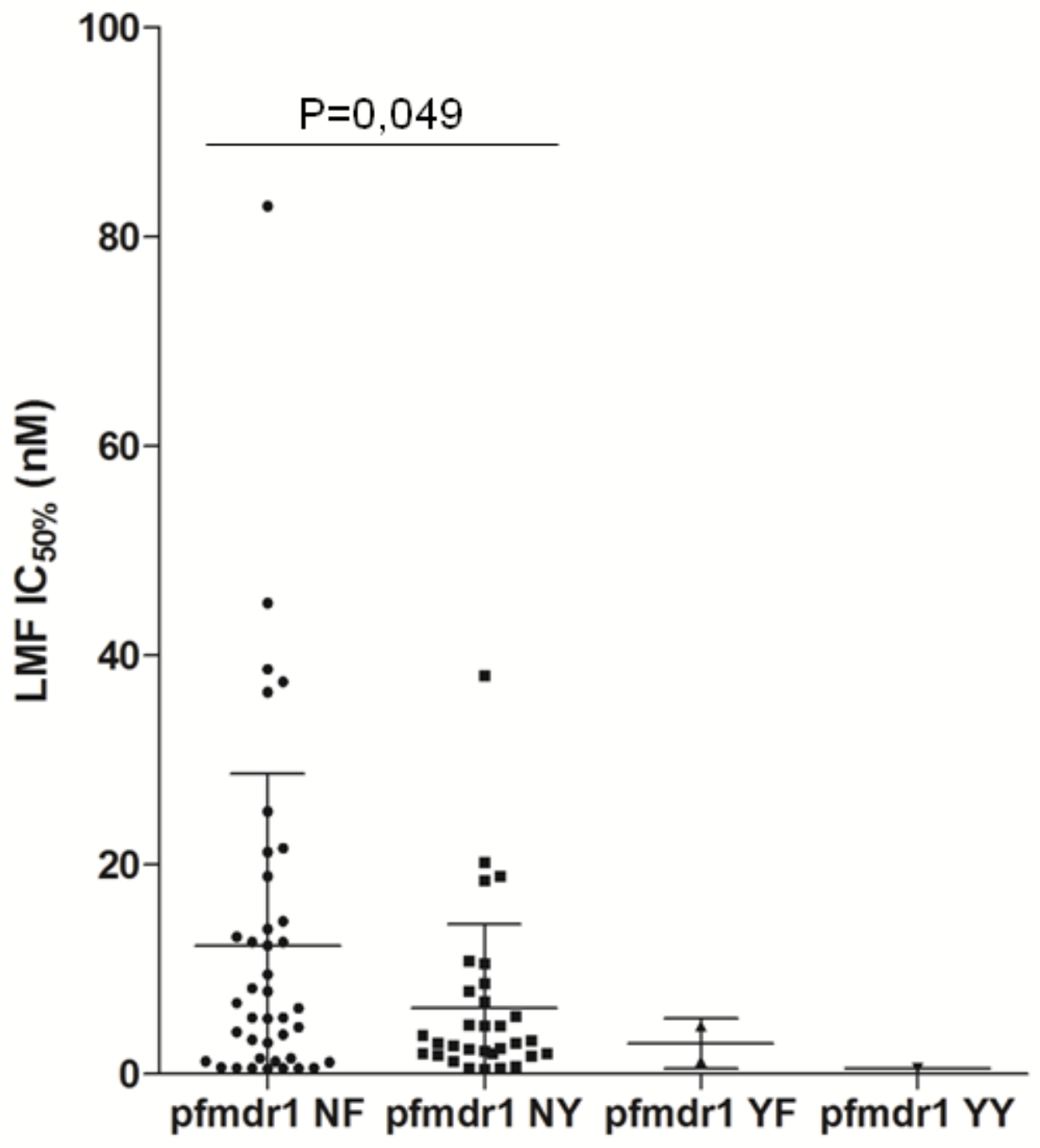


Antimalarial drugs in vitro testing

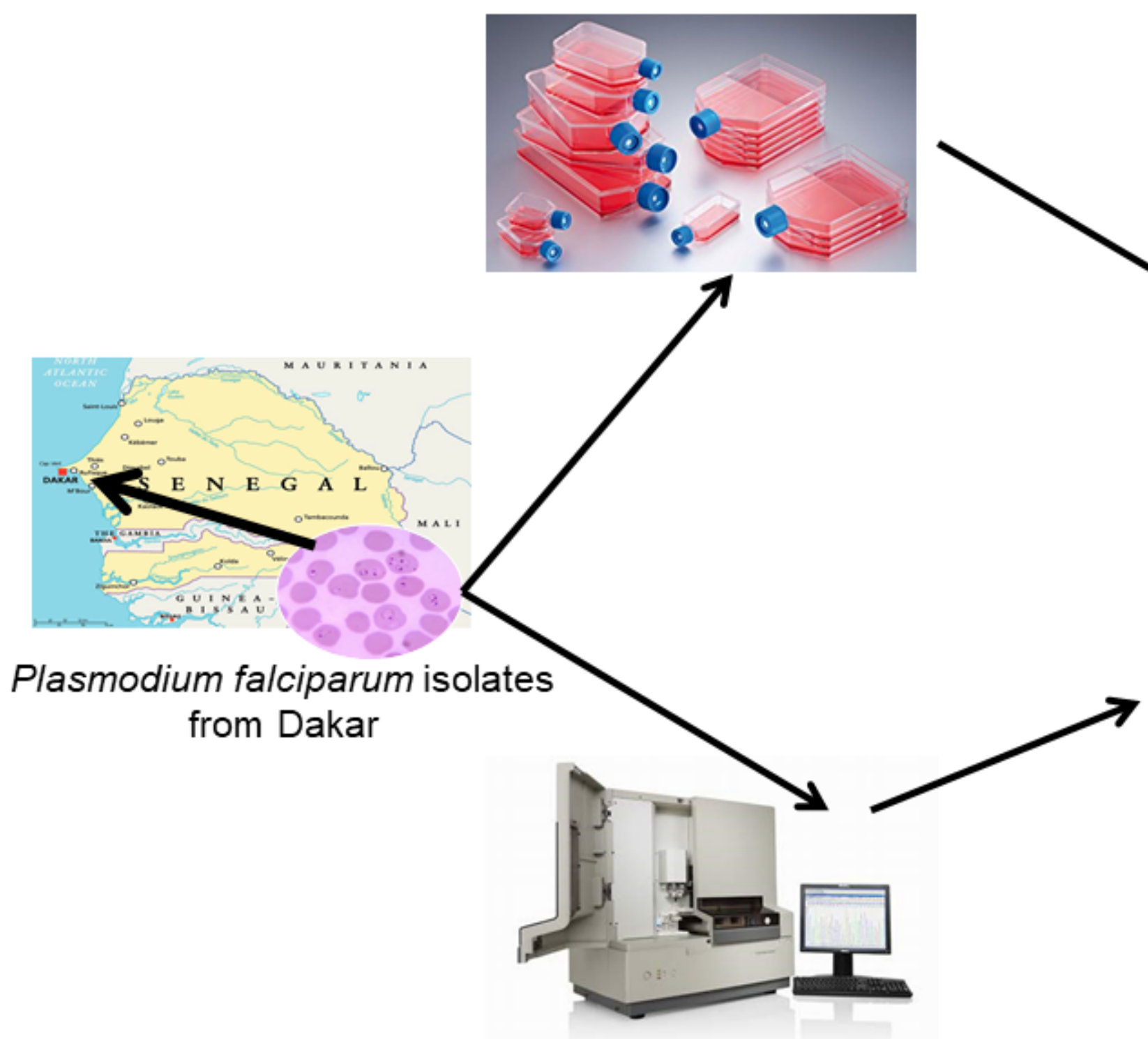

Sequencing of the ATP-binding cassette transporter genes pfmdr1 and pfmdr5 